From needs to deeds : where is pedagogy in changing the working and learning environments on a university campus?

\title{
Sandström, Niclas
}

2020-03-19

Sandström , N \& Nevgi , A 2020 , ' From needs to deeds : where is pedagogy in changing the working and learning environments on a university campus? ' , Journal of Corporate Real Estate , vol. 22 , no. 1, pp. 1-20 . https://doi.org/10.1108/JCRE-01-2019-0003

cc_by

publishedVersion

Downloaded from Helda, University of Helsinki institutional repository.

This is an electronic reprint of the original article.

This reprint may differ from the original in pagination and typographic detail.

Please cite the original version. 


\section{From needs to deeds Where is pedagogy in changing the working and learning environments on a university campus?}

Working and learning environments

\author{
Niclas Sandström and Anne Nevgi \\ Department of Education, Faculty of Educational Sciences, \\ University of Helsinki, Helsinki, Finland
}

Received 12 March 2019 Revised 14 July 2019 Accepted 19 September 2019

\begin{abstract}
Purpose - This paper aims to study a change process on a university campus from a pedagogical perspective. The aim of the process, as expressed by facilities management and faculty leadership, was to create campus learning landscapes that promote social encounters and learning between students and researchers, as well as other embedded groups. The paper addresses how pedagogical needs are or should be integrated in the design process.
\end{abstract}

Design/methodology/approach - The data of this case study regarding change on campus consist of semi-structured interviews of information-rich key stakeholders identified using snowball sampling method. The interviews were analysed to find common themes and reference to pedagogical needs and expectations.

Findings - Campus usability and reliability are improved when pedagogy informs the design, and needs such as sense of belonging (human) and connectivity (digital) are fulfilled. User-centred design should be followed through during the whole campus change process, and there should be sufficient communications between user groups.

Research limitations/implications - The discussion is based on one case. However, the recommendations are solid and also reflected in other related research literature regarding campus change initiatives.

Practical implications - The paper states recommendations for including pedagogical needs in campus learning landscape change and underlines the role of real user-centred processes in reaching this goal.

Originality/value - The study introduces the concept of campus reliability and highlights a missing link from many campus change cases - pedagogy - which is suggested to be essential in informing campus designs that produce usable and reliable future-ready outcomes.

Keywords Higher education, Co-design, Basic needs, Campus retrofitting, Learning landscapes, Pedagogical campus development

Paper type Research paper

Space is rigid but activity is flexible.

(Wu, 2018)

\section{Introduction}

Campuses are first and foremost spaces and places for learning. Universities still base their core essence on high quality teaching that in turn is based on high-quality research.

(C) Niclas Sandström and Anne Nevgi. Published by Emerald Publishing Limited. This article is published under the Creative Commons Attribution (CC BY 4.0) licence. Anyone may reproduce, distribute, translate and create derivative works of this article (for both commercial and noncommercial purposes), subject to full attribution to the original publication and authors. The full terms of this licence may be seen at http://creativecommons.org/licences/by/4.0/legalcode

This work was partially supported by a spearhead project, DigiCampus, funded by the Ministry of Education and Culture of Finland.

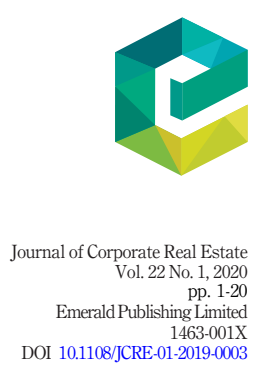


JCRE 22,1

However, when campuses are designed and retrofitted, it seems that the pedagogical perspective and instructional needs either are forgotten or play a minor role in the process. An additional complexity is brought in by digitisation and digitalisation (the digitisation of existing processes and practices, and the completely new practices and ways of learning, teaching and processing data, respectively). For instance, Duderstadt (1998) discusses the changing body of students and particularly what people expect from higher education, with a shift from just-in-case education to just-for-you education and ubiquitous education taking place everywhere, at any time and all the time.

The complexity of technologies and applications, assessment systems and learning platforms combined with physical facilities requires approaches that overcome the traditional silos of expertise. When campuses are developed to meet the needs of current and future users, the involvement of also experts with an understanding of both pedagogy and the hardware and software used in teaching and collaboration is called for (Sandström and Nevgi, 2017). Currently, pedagogical developments in higher education stress the importance of collaboration in knowledge creation and active learning (Paavola and Hakkarainen, 2005), and this is suggested to be effectively supported by flipping the classroom and learning (Abeysekera and Dawson, 2015). In flipped classroom pedagogy, the student's effort is transformed from a passive activity to more engaging activities that focus on the students. Acquainting oneself with the study materials takes place before the formal learning situation, highlighting the role of coming together to learn and study and to elaborate on ideas and knowledge.

Obviously, the involvement in the change process of the academics themselves is mandatory. Furco and Moely (2012) list key conditions that are important in supporting faculty with instructional innovations. One of them is the perceived institutional commitment to provide support and maintenance of the innovation (see also Young et al., 2007). The seamless digital solutions, facilities development and innovations should thus be built so that not only are the faculty members part of the process, but additionally, have trust in the longevity of the changes towards better teaching and learning environments.

When embedding new space typologies, learning approaches and collaboration platforms in the digital-physical interface on campus, higher education institutions also take a pioneering role in developing the built environment and services within and outside the organisation's walls (Eriksson et al., 2015; Nenonen et al., 2016). As Wu (2018, p. 237) writes, "[s]pace is rigid but activity is flexible." Higher education is at the heart of high quality learning and teaching, and user needs evolve with changes in the working life: sharing, co-working and creativity have become key concepts on different levels of society in the age of knowledge economy. Keeping in mind the fact that the need for universities to transform themselves has been discussed for long, these dimensions put pressure also on university campus development, when research and studying are ever more global and take place in networks with more diffuse time and place boundaries (Nenonen and Lindahl, 2014; Kojo and Nenonen, 2016).

What seems to be either lacking or given little attention in research approaches to campus development is the systematic integration of pedagogical design and thinking. The operational side and practices are separate from the academic and pedagogical side of the institution (Savanick et al., 2008), and educational leadership is mostly seen as belonging to curriculum development, not as an overarching dimension that touches the whole university. One of the key issues for a pedagogical campus developer (i.e. an educational researcher and expert that collaborates with both FM and academic leaders - such as Heads of department, Deans and the Rectorate - and that works in the nexus of FM and educational leadership) is the fulfilment of basic and psychological needs in the built environment (Sandström et al., 2016).

Sjöblom et al. (2016) discussed the psychological basic needs (such as relatedness and competence; see e.g. Deci and Ryan, 2008; Gay et al., 2011) in the context of a physical learning 
environment, concluding that the fulfilment of the needs might be a prerequisite for a sense of belonging in the professional community to emerge. These needs have in the recent years, along with digitalisation, been challenged somewhat when the time and space boundaries fluctuate more and learning and working becomes more mobile (Dugdale, 2009; Harrison and Hutton, 2014; Neary and Saunders, 2011). An additional layer to the "traditional" needs has been suggested to be that of wireless connectivity, i.e. Wi-Fi. However, despite the transformations on the digital front, the basic human needs (Maslow, 1970) remain essential and unchanged.

In the following chapters, first the theoretical grounds of the study are outlined. After this, the method is described, then the findings and last, practical implications are given together with ideas for future research.

\section{Drivers of space design: towards pedagogically meaningful and future-ready campuses}

Universities and higher education institutions old and new have started to pay increasing attention to the need to design facilities that are activity-based and flexible (den Heijer, 2011; Samson, 2013; Sankari et al., 2018; Kärnä et al., 2013). One example is the Oxford Centre for Creative Research (OCCR), whose main tenet is to bring together like-minded staff to foster collaboration across disciplines among researchers in the Humanities (Young et al., 2017), known for its rich and varied domains of scientific practice. Like-minded people need spaces for collaborative work, and nowadays also in universities, different hub ecologies and more informal environments are indeed on the rise (Nenonen et al., 2016; Rytkönen et al., 2015; Sandström and Nenonen, 2019). In this paper, the focus is on the pedagogical holding environment on campus, where working and learning spaces should not be siloed and separate but rather, form a continuum where spaces for teaching, learning and recreation are occupied by different users. Space is here understood as more abstract and continuous. Place, on the other hand, is a human product that according to Pred (2014, p. 128) "always involves an appropriation and transformation of space [...]". Place, thus, is more grounded and evokes in people a sense of belonging (about sense of belonging, see Discussion).

Sankari et al. (2018) studied the benefits of co-working spaces for academic space users, concluding that e.g. multipurpose office, attractiveness and community are appreciated by academic communities. The students they studied hoped for decentralised spaces that enable a sense of community and the ability to ask for and give advice, between students and faculty. Open, activity-based environments would add flexibility also in academic communities, similar to other urban ecologies (Brown and Long, 2006). What differentiates them from more traditional environments is the fact that they are based on contextual and emerging needs that workers and learners have or are supposed to have; see e.g. Hoendervanger et al., 2016. Spaces should be designed with learning in mind (Van Note Chism, 2006).

\section{User involvement and co-creation: Collective design as a means to transform learning landscapes}

Campuses can be seen as broad and established learning landscapes that are an essential part of their urban surroundings. Campuses are learning and working environments that are intertwined with urban structure and services (Harrison and Hutton, 2014; Scholl and Gulwadi, 2018). In this paper, we look at a change process on campus using as the focal point an area of approximately 1,000 sqm that were retrofitted on two interconnected floor plans. The scale - the learning and working environment in one building completed in 2005 - is

Working and learning environments 
JCRE 22,1

intertwined with the broader picture (the campus scale) through intertwined processes between students, faculty, FM and administrative staff.

It is acknowledged that people look at the campus environment through their respective lenses, i.e. learning and working environment. Despite the focus being on a rather limited area on campus, the different layers (learning environment, working environment, learning landscape, campus) of the scale are interconnected and thus, are here discussed as components of a continuum.

"Learning landscapes" has been used to refer to educational reforms and transformations as well as to changes in how teaching and learning spaces are designed (Chiddick, 2006; Dugdale, 2009; Harrison, 2006; Harrison and Hutton, 2014). The Council of Europe (Council of Europe, 2000, Article 1 a) has defined landscape as "an area, as perceived by people, whose character is the result of action and interactions of natural and/or human factors." We add learning as in learning landscape, to refer to the formal, planned, informal, more unplanned and other services and space-place continuums that either provide and produce learning opportunities or support people's learning and study activities. When compared to Vallés-Planells et al. (2014, p. 1) definition of a landscape as a "holistic, spatial, and mental dynamic entity, which is the result of people-place interactions", we have a holistic and comprehensive definition that covers the needed components.

These landscapes entail the spaces that each user group occupies and between which the different users move and perform task-specific activities. New learning and teaching approaches, space typologies for creative work, and globalisation have an impact on what kinds of spaces will be built and how existing property will be re-designed and retrofitted (Rytkönen et al., 2016; Neary and Saunders, 2011). Activities are fluid and flexible, whereas spaces are more fixed and rigid. The key question when designing for the future is to find the tensions between expectations and the possibilities that there are for improved landscapes.

Finding the tensions and expectations requires participation - and more, according to some researchers (Sanders and Stappers, 2008). This can be achieved using collective design, which entails more than mere ad-hoc influence and participation by commenting on drawings etc. (Nenonen et al., 2016, p. 4). It is a process where knowledge and values confront, complete and modify each other leading to something new. However, obviously not every process requires the involvement of users: streamlining the automated doors to a building might not call for user involvement. When the question, however, regards how the users experience e.g. a space, a product or a service, user-centred design is called for involvement is beneficial from analysis through synthesis to decision (Sleeswijk Visser et al., 2005). We apply the terms "co-creation" and "collective design" to refer to a collaborative effort by both architects and designers and end-users with little or no training in design, to achieve mutual understanding of the user needs and of the possibilities that the facilities on campus can produce after retrofitting. Co-creation and collective design can take a formal (mediated by tools, processes, facilitators etc.) or a more informal (taking place 'on the job/ duty') shape, but when formal, there is a bigger chance that the involved users see their input in the outcome. In collective design, everyone involved is regarded as an expert, and their participation is therefore based on their relevant knowledge rather than on their roles as representatives for different interests (Könings et al., 2014; Granath et al., 1996).

On campus, it is essential that the spaces and the built landscape support learning in its different forms (Beckers et al., 2015; Matthews et al., 2011). In the ever-globalized and constantly interconnected world, the demands that university institutions face have changed radically over the years (Harrison and Hutton, 2014; McLaughlin and Faulkner, 2012; Sandström et al., 2014; Sandström et al., 2016). The emergence of new online learning 
environments and digital solutions has modified the conception of time and space leading to the illusion that the physical 'place and context where the learning takes place is not very important' (Gros, 2016). A growing tendency on different campuses is to re-adjust existing spaces that no longer serve the purpose they used to serve, for new kinds of activities, learning and work. This process is called campus retrofitting (CARE; Nenonen et al., 2016). The aim in holistic retrofitting processes is to change existing spatial solutions so that they meet current users' socio-digital reality. In a holistic CARE process, all the main key stakeholders and their concerns should be involved (Nenonen et al., 2016).

In the broad retrofitting view, the role of behaviours and motivations behind the process and in the outcome are taken into consideration. Usability is best reached using co-design and iteration to produce ownership of the outcomes and the process (Nenonen et al., 2016). In activity-based CARE, the process is iterative, consisting of a shared vision, results and costs between owners and users on campus. This way, sustainable, future-ready and usable campuses can be developed. The essence of usability is in the emotion: it is the core of any usable - or poorly usable - built environment (Kojo and Nenonen, 2012).

Staff and faculty typically work in separate organisational and campus cultures (Savanick et al., 2008), and interactions between faculty and management often do not communicate e.g. pedagogical issues or academic culture (Kuntz et al., 2012). Because there seems to be a lack of research on how pedagogical thinking and pedagogical requirements are integrated systematically into the process during campus retrofitting, we took a pedagogical campus developer's look at learning and working space change process on campus. The process studied in this paper was chosen because the space that was redesigned has been supposed to reflect new pedagogical ideas that are being implemented in the university's context.

\section{Research questions}

To understand what happened during the change process, we first posed the following research question:

$R Q 1$. What was the change process like pedagogically and who participated in it?

In addition, after identifying the change process, our second research question focussed on how the process addressed pedagogical needs that were emergent in the stakeholder expectations.

$R Q 2$. How were the expressed pedagogical needs implemented in the retrofitted campus landscape?

\section{Methodology}

Context of the study and the change process

The context of the present study is the space left unused by a faculty library in the Centre Campus of the major Finnish University that is located in the city centre. On the faculty level, there was a wish to design and test new kinds of spatial typologies for learning and working, also to promote social encounters - formal and informal - between students and the research community. The upper floor was designed to become an activity-based environment for researchers and the lower floor, a Learning Centre for students. The staircase between the floors combines the two spaces. In Figure 1, the changes, having been performed simultaneously, of the retrofitted campus environment are illustrated in layout form. 
JCRE

22,1

6
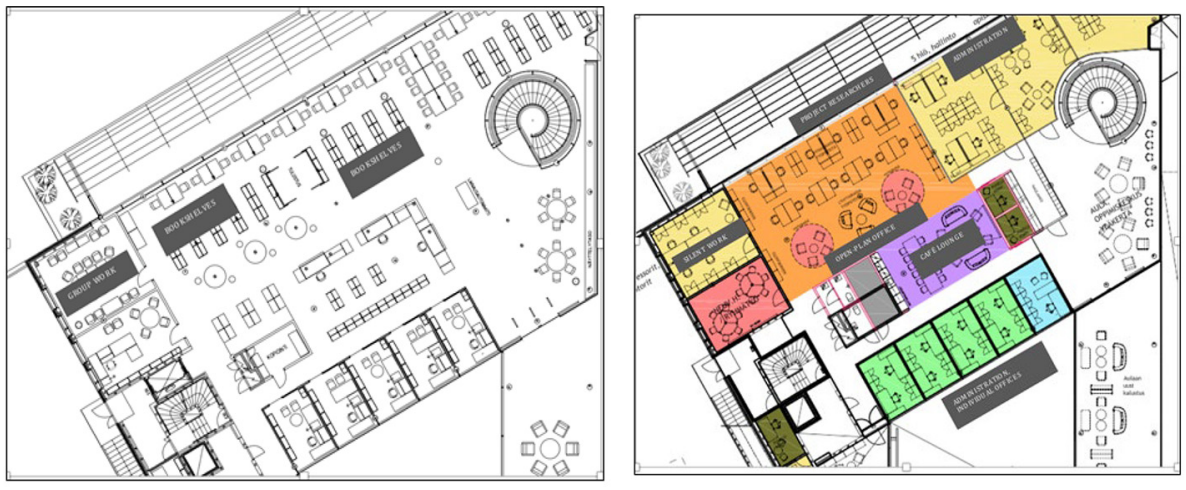

(a)
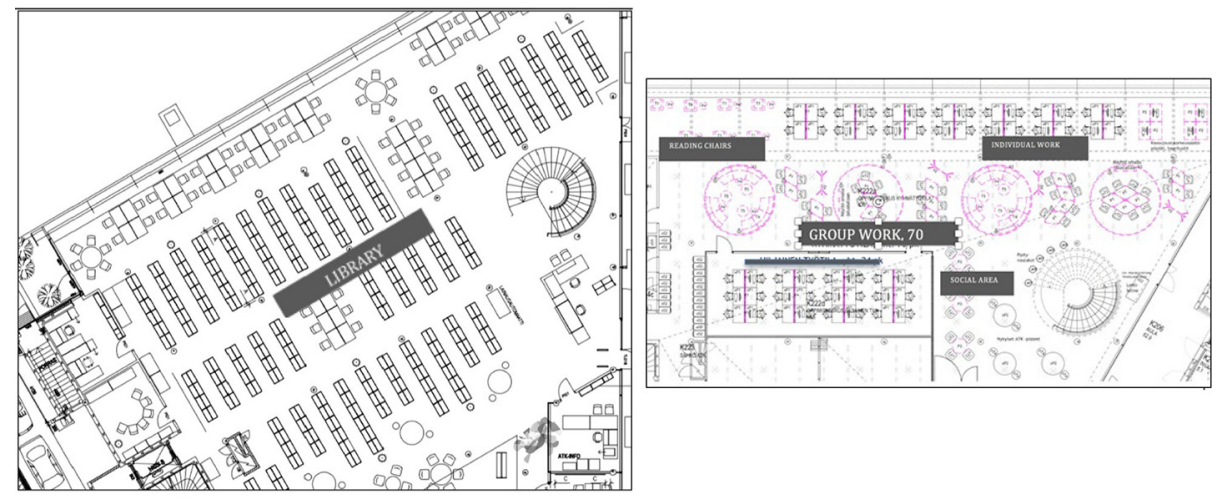

Figure 1.

Layouts of the retrofitted campus environment before and after the change process (b)

Notes: (a) The floor plan of the Library space (upper floor) before and after retrofitting the space as activity-based working environment for faculty and meeting space for researchers and students (staircase leading to the Learning Centre); (b) the floor plan of the Library space (lower floor) before and after retrofitting the space into Learning Centre (staircase leading to retrofitted Faculty floor). The plan after (purple dotted lines = acoustic curtains for group work) with silent space for individual work separated by a door

\section{Data and research procedure}

The data used in this study consisted of observation notes, design documents regarding the retrofitted space, thematic semi-structured interviews and a shared online research diary that was compiled by both authors always right after the interview, summarising the main points and ideas that the interview had evoked.

The interviews were performed by both authors, and combined with visual material shown to the interviewed information-rich stakeholders. The material depicted the layouts of the physical design proposals and layouts of the spaces before the change process. Informationrich key stakeholders were selected using snowball, i.e. chain sampling method (Patton, 1990). Using the chain sampling method, the active stakeholders in the campus community (FM, educational leadership, pedagogical ICT support, student services and students) were traced 
and contacted to be interviewed. The question asked to establish the information-rich key stakeholders was, "Who were involved in the campus change process?" The number of active information-rich key stakeholders saturated at $N=11$, representing all the users that were involved in the actual retrofitting process and the collective design choices that were taken.

The thematic interviews were carried out in May and June 2017. The interview themes focussed on the following topics:

- starting point - original ideas to design pedagogically meaningful activity-based environments;

- change process - how the original ideas changed during the process yielding the outcome; and

- end-users' evaluation of the outcome, including digitisation and digitalisation.

The interviews were conducted by both authors as individual $(n=8$, faculty management, FM, student services, pedagogical ICT support, and a student) and as a focus group ( $n=3$, students). For reasons of anonymity, we refer to all the stakeholders cited in the paper using the female pronouns 'she/her'. The interviews lasted $54-64$ minutes and were recorded and transcribed verbatim.

\section{Analyses}

First step of analyses yielded a mapping of the phases of the change process and what kinds of communications occurred among key stakeholders and their reference group during the change process. The second step of the analyses concentrated on analysing the interviews, and the shared research diary. At the beginning of analysis, the authors read the transcribed interviews and the notes in the shared research diary individually and identified the emerging themes, and created preliminary categories, after which they discussed discrepancies in the analysis until they reached an agreement through comparing units within the same case (Yin, 2009).

The authors continued to validate the analysis based on the preliminary categories to identify stakeholder experiences concerning the retrofitting process and the outcome. In addition, sense of safety and sense of belonging emerged as categories from student interviews. The advance organiser that was formed based on analyses is presented in Figure 2 below.

\section{Findings}

Discontinuity in the space occupancy process

The first research question regarded how the change process was (Figure 3). The phases were identified based on both the analyses of the design documents and on analyses of the
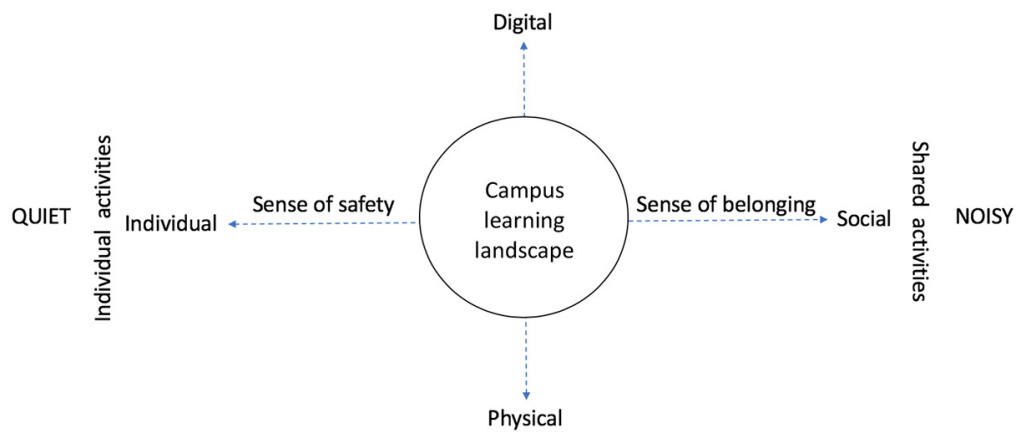

Figure 2.

Advance organiser for dimensions identified in a campus environment 
JCRE 22,1

8

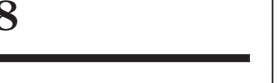

Figure 3.

Phases of the change process identified retrospectively during analyses of documents and interviews

\section{Figure 4 .}

Dimensions of a campus learning landscape

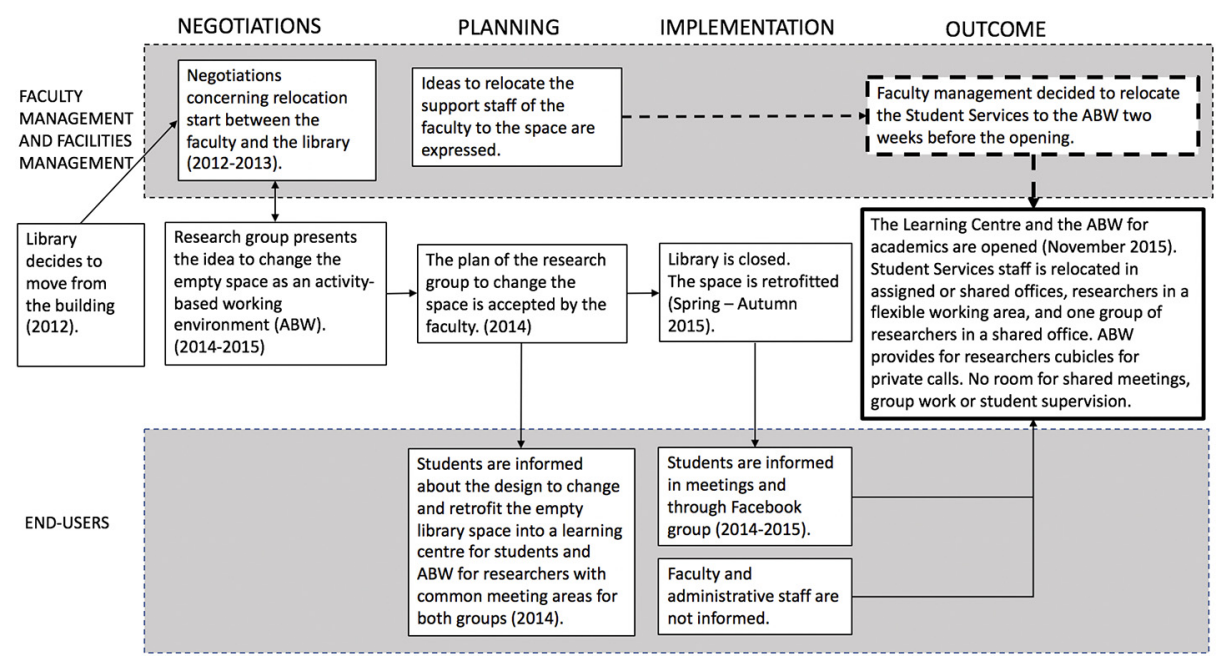

thematic interviews. Both on FM and faculty management levels, there was an identified need to change the spatial solutions. This change also had to do with a strategic need to cut down on facilities expenditure. One of the main tenets in FM and Faculty management was to create spaces that would bring together students and researchers in informal ways. The re-designed spaces were planned to be enriched with embedded digital solutions supporting co-creation and sharing. The overall process is depicted in Figure 4. The library wanted to keep students on board the changes, and invited them to participate through e.g. a Facebook site and through discussion events. However, during the interviews it became evident that the faculty or administrative staff were not involved in the pedagogical or other workplacerelated design of the process, and were mostly unaware of the changes.

What, then, happened during the final phases of the process? According to stakeholder reports, there was a dis-communication at some late stage. This change was perceived in two ways: first, the layouts that had been discussed with the stakeholders had changed; second, there was a seemingly sudden change in who would eventually be relocated to the

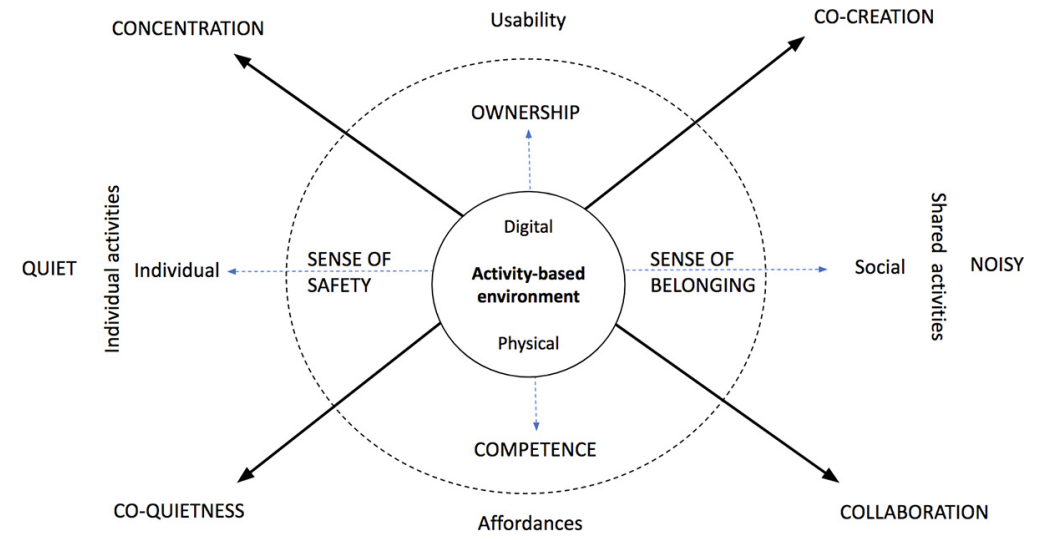


new activity-based environment, and groups other than the ones involved in the initial concept also occupied a noticeable amount of space in the new environment. This resulted in a situation where the end-users that finally occupied the spaces did not participate in the decision-making. From the perspective of a pedagogical campus developer, such gaps in the process are challenging in terms of the expected outcome, and the occupancy process is not aligned. Due to dis-communication and discontinuity of the change process, the expected informal meeting spaces for researchers and students were not created. In addition, studying the change process, a post-occupancy evaluation (POE) regarding e.g. user satisfaction or design review was not performed.

On the Faculty and FM levels, there were some visionary ideas about the possibilities that the spatial retrofitting and short-distance relocation could have in terms of social encounters between embedded groups. The relocation and retrofitting process had originally been seen as a chance to make a difference and increase communication between embedded groups. The students stated that there were eventually few attempts to create a common meeting space for students and researchers and teachers. The students expressed that they had been able to contribute during the retrofitting process, and they felt that the process had been participatory. Nonetheless, they also reported that only a small number of students were involved in the change process. The process was experienced as quite hectic, and there had not been a particular plan that could have been executed.

\section{Key stakeholders' needs regarding the outcome}

The dimensions of the campus learning landscape that were identified from the interviews were categorised as follows:

- physical environment;

- digitisation and digitalisation;

- social; and

- individual environment.

Table I summarises the information-rich key stakeholders' perspectives arranged according to the dimensions. Two additional dimensions that emerged were an experienced sense of safety and sense of belonging. Student reports reflected these dimensions with regard to for instance the transparency of the spaces (glass walls that add to visual presence), the furniture (reading chairs that provide visual and acoustical shed) and the stability of the networks and devices that support learning and task fulfilment.

\section{Pedagogical needs concerning physical and digital environment}

One of the main aims of the change process was to create a learning landscape where researchers, students and staff from student services could meet informally in a common meeting space. However, the outcome of the process had yielded separate and differentiated spaces for students and a separate working environment with both flexible working spots and own offices for researchers and student services. A member of Faculty management stated, at entering the activity-based environment that, "Yeah, we [the ones with access to the office] are definitely seen as some kind of weird people that disappear behind closed doors." The barrier, thus, is small but decisive. The changes in the physical environment did not support students in having an easy access to meet teachers and researchers and students' pedagogical need for supervision and guidance did not materialise.

Between the learning plaza and the retrofitted learning centre, there is one door that is locked, and discussing their digital integration led one student to state that: 
JCRE

22,1

10

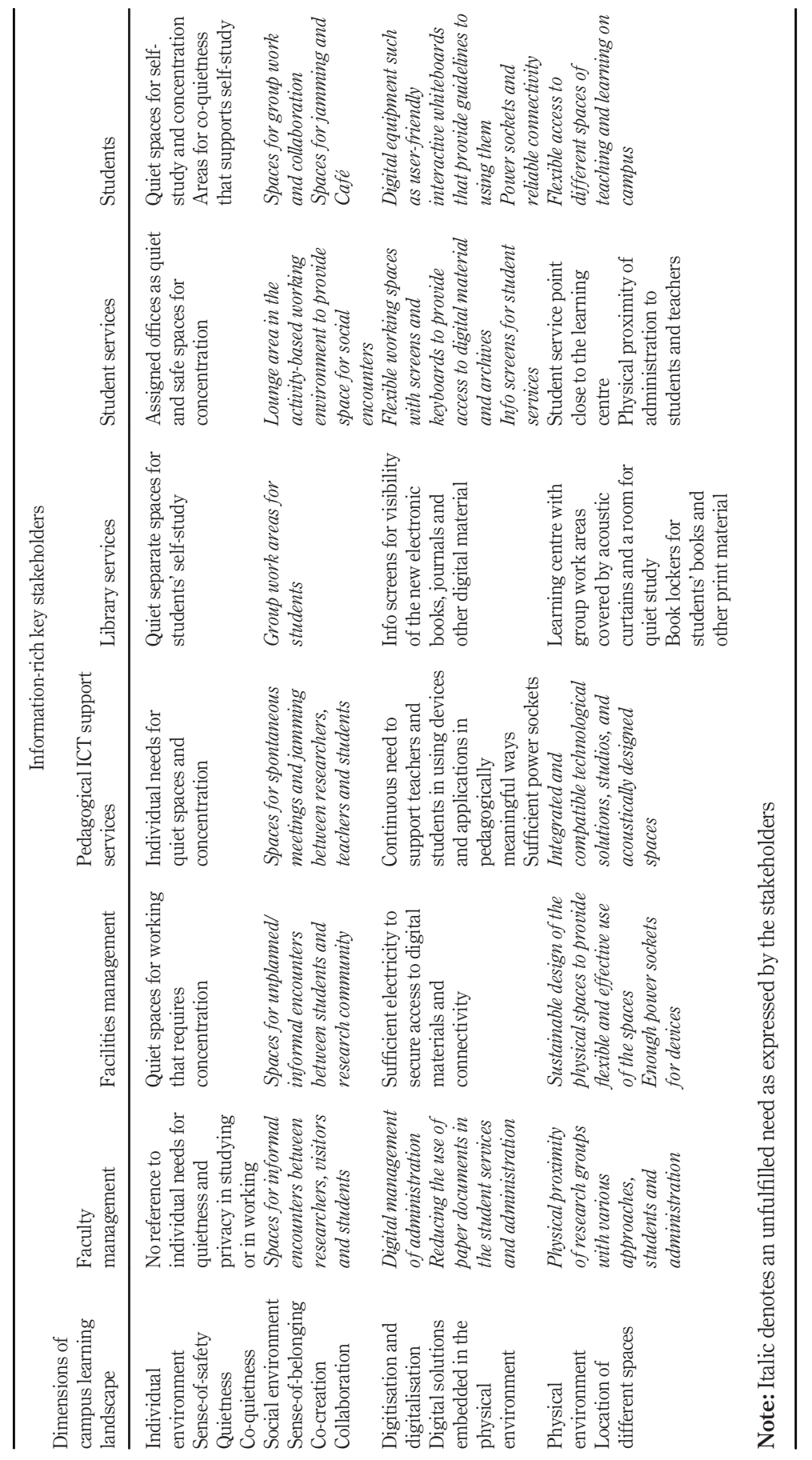

Table I.

Pedagogical needs expressed by key stakeholders regarding the change process 
Well if that's the goal, then the first step is to unlock the door down there [between the spaces] like [...] no-one is like dynamically moving between the spaces [ . . . .

The spatial configuration and small hindrances between spaces were seen as unfortunate, with embedded digital solutions not strongly supporting interaction or communication and learning processes as such, because the spaces are separated and one cannot freely move in them.

One student described the hallway area in front of the locked activity-based workspace and added that:

There is a need for general spaces where natural encounters can take place, so that the spaces are not separate for the different [research and other embedded] groups [. . . ] For instance changing that hallway into some kind of a hanging-out - café area [...].

During the process, the idea to relocate student services close to students had arisen and student services were located at the far end of the open hallway. The key stakeholder from student services expressed that to relocate student services close to the learning centre provided for students an easy access to the services. Interestingly, the students thought that such a prime spot with a sea view should be open for pedagogical activities such as group work and meeting supervisors. They described the spot as an excellent place for social encounters. One student said:

It has the best view, I've been thinking about it as an area for groups and get-togethers, like a place where everyone can watch the sea view.

They said that student services need not be located on that spot, as students rarely go there anyway and because, as one of them stated, "If you've once found the right place, you will find it again".

A common observation was that clear practices and user-friendly instructions are needed for the digital affordances to become actively used as well in teaching and learning as in research. According to most of the key stakeholders, a "digital leap" cannot be taken if the leap is only seen as the acquisition of more hardware in classrooms and other learning spaces. According to them, the technologies were not embedded and neither the teachers nor the students were given support in how to use them, and the acquisitions were rendered meaningless or did not benefit them.

Students stated that for studying and learning, there should be more and more wellfunctioning technological tools such as computers, as they need to be able to rely on the fact that they have computers with programmes they need in their studies. Students pondered whether a very digital solution was really something that was sought after in the first place, although there had been a hype earlier in the process about building a very modern environment. The students also shared ideas about how to take the screens and digital tools in more intensive use. One of the ideas concerned the "smartness" of the smart screens and why the screens themselves could not instruct users:

Why doesn't the smart screen advice by itself how to use it [ . . . There could be like a text saying "hi, I am also here, you can use me like this-and-this, and you can also do this with me.

The library manager stated that the e-materials are not as visible as they should be (especially compared to the book-driven era), and searching for information or finding the novelties in different fields poses a challenge for easy access to databases. Stakeholders reflected that many times the vision is implemented by acquiring more devices and applications without a clear idea of how they support learning or of how
Working and learning environments 
JCRE 22,1

users actually make use of them. One of the ICT interviewees put it as, "Like from no devices to we have devices". The idea that she puts forth is that usually, acquisitions are done without facilitation and maintenance to support users.

The ICT support interviewees mentioned that for most people it is easier to use low-tech affordances such as whiteboards and paint walls for sharing ideas and co-creation. They highlighted that even though there are digital or high-tech affordances for co-creation, it often seems quicker for users to start elaborating ideas on low-tech surfaces. After that, the process can be digitised.

From the students' perspective, the redesigned campus learning landscape provided only limited access for them to various physical and digital environments and thus their needs for pedagogical support were met only partially.

\section{Pedagogical needs concerning social and individual environment}

The campus change process had been a visionary change for some of the interviewees. Both the Faculty management and FM mentioned an underlying wish to break bureaucratic boundaries with help of the spatial transformation and short-distance relocation. Still, the underlining bureaucratic boundaries existed after relocation, as reflected by the student services stakeholder in her interview, "There is an invisible boundary there [points a finger to show the direction], by the flexible desk area." According to the students, the physical surroundings should enable unplanned social encounters, which they found not to be the case currently. As one of them said, "It is still so that researchers disappear upstairs and students go downstairs to the basement."

Both the students and other participants emphasised that the environment should provide spaces for both individual learning and for shared learning activities and jamming. These meeting spaces were hoped to exist also in other areas of the building and next to the space for researchers, not to be restricted only to the Learning Centre itself. Furthermore, all students highlighted the need for more spaces and areas for group work.

Students reported that for individual learning activities, the space should provide intimacy, safety, and support for concentration on learning. They emphasised that the space should be both visually and auditorily quiet so that they could feel safe and surrounded by people performing same kinds of activities. They also expressed a wish to be able to do individual study and that the space should afford a possibility that we here call co-quietness (studying quietly together without a specific shared learning activity). Being able to form some kind of privacy even in the co-quietness was considered important, and helpful in experiencing safety. The students and the library management expressed an interesting tension between willingness to learn more by using digital possibilities for sharing, producing and co-creating on the one hand, and the need for silence and co-quietness and privacy on the other.

All the interviewed students reported that the campus provided them with a safe environment to study and meet other students. A student said, "It feels very safe. I have never felt unsafe." Students stated how important it is that the campus environment provides spaces to meet and collaborate with other students and also with the researchers and teachers, as they like to feel that they belong in the academic community. One said, "[o]ne of the most central issues currently is that there should be spaces for students to gather and work on shared topics." They also reported that the academic community was only a dream, the building itself expressing the hierarchical structure of academia where students hold the lowest position. They described how the staff might introduce themselves, "being from the fourth floor", after which the 
students would tell the staff that their spaces are in the basement. Their conclusion was that environmental factors such as location within the building, "have a very big impact on the power structures and positional status." They expressed a strong thrive to be a part of the academic community.

The ability to create knowledge and learn and work in a reliable campus environment is supported by a sense of ownership of the spaces and processes as well as a sense of competence (knowing how to work one's way in different situations and spaces). Figure 4 summarises the dimensions as a holistic, ideal picture of what should be kept in mind when designing a well-functioning campus.

\section{Discussion}

\section{What actually happened: pedagogical perspective on the campus change process}

The outcome of the campus change process described here posed challenges from a pedagogical developer's perspective. First, the outcome did not follow through with the principles laid out in meetings between facilities management and the end-users, and the outcome seemed to be a compromise on various levels. Second, the campus change process yielded differentiated areas for students and researchers, highlighting the traditional view of university with spaces for academics to teach and meet students and different spaces for working. Overcoming this challenge would require an integrated view of educational leadership as part of the process on its different levels, helping to achieve pedagogical goals also in facilities design. Thirdly, a holistic collective design process was not followed through, except for some meetings that were organised to inform e.g. students. End users such as researchers and teachers seemed to be absent from the change process. Finally, examining and analysing the phases of the change process revealed that a POE such as an overview of user satisfaction or review of design was missing, a finding in line with Hay et al. (2017) regarding POE in architecture.

As in a workplace change case discussed by Skogland and Hansen (2017), the metaphor and design principles used by designers and corporate project management differed vastly from how the employees experienced the new workplace design: The strategy failed to reflect the values of the workplace, as the employees did not experience the design to support their workplace behaviour in ways that they had been before the change. In a similar manner, the change process in the present study failed to meet the values and pedagogical needs of end users. This case speaks for the importance of co-design and usercentred design throughout the change process, so as to be able to integrate pedagogy to shaping the outcome.

\section{Add pedagogy to the design process: What needs to be taken into account?}

From a pedagogical campus developer's perspective, we set out to understand what the stakeholders were actually saying concerning the outcome of the retrofitting process. Comparing the present results with previous studies about learning environments and basic psychological needs (Sjöblom et al., 2016), the stakeholder reports reflected human basic needs on various levels. For instance, the FM representative predominantly spoke about the physical spaces, whereas the students mentioned factors such as safety and community. Academic communities often over-emphasise competence and autonomy (Ryan and Deci, 2002), whereas basic psychological needs such as sense of safety and belonging are seldom taken into consideration (Sandström et al., 2016; Sjöblom et al., 2016). 
JCRE 22,1
Figure 5.

Basic needs for reliable campus learning landscapes
Sense of safety can also be produced through physical design and layout, but the social dimension is as important. Also, a sense of belonging can be supported by the physical facilities, as suggested by e.g. Sandström et al. (2016). In a case study of a blended, technology-rich campus environment (Sandström et al., 2016), the participants reported that a well-functioning wireless network, technologies and digital solutions made them go to campus to work on their shared tasks, even when they could've stayed at home or meet at a group member's place. In the campus environment studied in the present article, the digital affordances and the need for both concentration and cocreation were met, but partially.

It seems that connectivity and power supply are parts in forming the backbone of modern campus usability. In the digital age, the human basic needs, following Maslow (1970), have been amended by wireless connectivity (Wi-Fi): to survive in the digital era, people need electricity and Wi-Fi. In fact, our interpretation in terms of the basic needs of the digital age supporting pedagogically meaningful learning landscape design, electricity and connectivity, is the following: what people are talking about is reliability in the fulfilment of these needs.

We use the concept of reliability to also address the primary digital age basic needs, electricity and connectivity, without which the pedagogical solutions remain ideals that do not materialise. If there is a fear of compromised outcomes in the integration of digitally supported pedagogical practices, those practices might remain theoretical at best and their full potential will not be met. In these cases, people actually lower their expectations and do not plan materials, practices or pedagogies that would depend on a well-functioning connectivity (Ertmer et al., 2012). Reflecting the results back to current pedagogies such as flipped classroom, it seems that campus usability and reliability at least partially equals fulfilment of pedagogical needs and requirements: different spaces and place-making possibilities are needed to shape a campus holding environment that supports learning and collaboration across borders.

Reportedly, when the student stakeholders in this study go to campus, they want to be sure that there are enough spaces for co-creation and collaboration as well as functional technologies used for specialised tasks, including statistical analyses. Reliability of the facilities is essential for usability and user satisfaction. Our proposal for the hierarchy of basic human needs of the digital age, informing the design and redesign of campus landscapes, is presented in Figure 5.

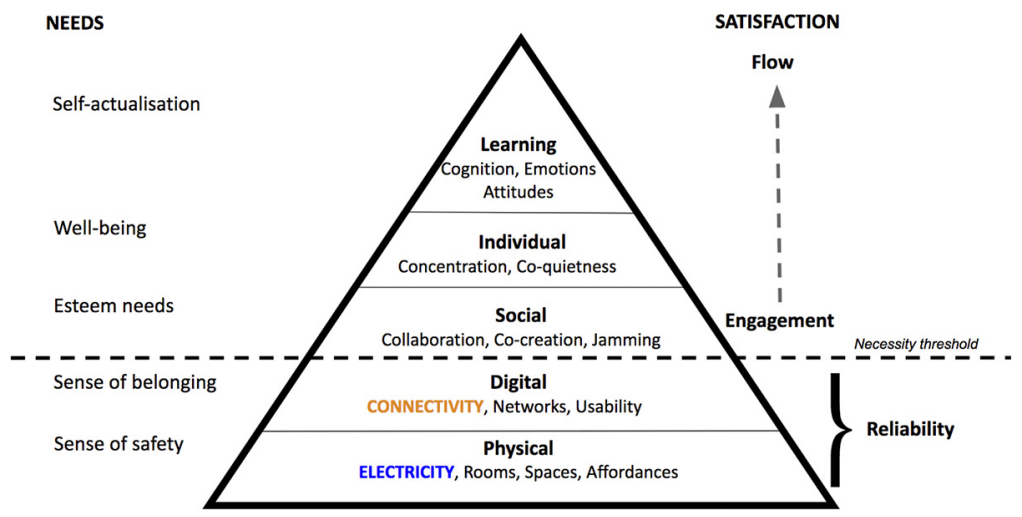


The threshold is at the same time the threshold for usability: users go to campus when it meets their needs. Levels of satisfaction require the stability of the foundations on which higher-level achievement can be built.

\section{Reflections on the reliability of the study}

The sample (11 interviews) was a saturation that was met when using the chain sampling (snowball) method to trace the information-rich key stakeholders. As a matter of fact, the sampling method revealed what turned out to be one of the key findings: a rather large and intensive campus change process - affecting different levels of actors on campus - was designed and effectuated based on a small group of stakeholders compared to the size of the faculty (approximately 400 employees and 3140 students) and the visionary passions reflected in many of the interviews. The representativeness of the sample is good in terms of how the study is limited: generalisations are made regarding only such dimensions of the process and rapport of the participants that can be discussed in light of the theoretical framework. The data were collected in one faculty only. However, when talking about for instance digital basic needs, it is to be expected that they do not fluctuate too much.

\section{Practical implications and future research}

Based on the re-interpretation done after Maslow's hierarchy of basic human needs, it seems plausible to say that viewing the change process with basic needs in mind is a way forward. Staff and faculty should have more communications regarding pedagogically meaningful and modern solutions, and they should communicate more and participate in the same committees. Pedagogy should not be considered a separate operational activity from e.g. facilities management.

Pedagogical relevance and meaningfulness should be an essential part of the design process and POE (Göçer et al., 2015).

\section{Recommendations}

In the case study described here, we set out to understand from a pedagogical campus developer's perspective what happened during a campus change process and to understand what kinds of pedagogical issues perhaps inform the design and retrofitted outcome. Despite the fact that the following suggested recommendations reflect empirically only one case study, the points present a condensed listing of issues that arose from our data. They are not intended to be exhaustive; nonetheless, the following recommendations underline some of the possibilities and challenges in turning campus retrofitting processes, on the one hand, and the actual outcomes, on the other, more pedagogy-driven:

- support impromptu, unplanned social encounters between different embedded groups by spatial solutions; These include open and transparent spaces that attract different users and lower administrative boundaries;

- anchor the digital affordances in the practices of the pedagogical holding environment; maintain a clear vision of what the tools can offer and how they can be used to enhance co-creation and learning;

- consider continuous facilitation, pedagogical user support and maintenance of technological tools and applications a necessary resource and a part in the digitalisation strategy;

\section{Working and learning environments}


JCRE 22,1

\section{6}

- communicate staff and faculty visions more openly and with pedagogy and learning in the centre;

- support a sense of privacy and sense of safety by both physical solutions and social facilitation; and

- secure the digital age basic needs by sufficient and rightly placed power supply and stable connectivity.

An embedded perspective in retrofitting the campus means radical changes in the overall alignment of pedagogy and facilities management. For instance, multi-purpose, activity-based informal working environments are an emerging spatial typology in different contexts also in higher education, as the concept of space and spatial processes is undergoing transformations (Rytkönen, 2015). It may well be that the pedagogical holding environment that campuses represent could benefit from what has been learnt about activity-based environments and their ability to support different kinds of processes (Sankari et al., 2018). Designing spaces for different phases of studying and learning can be effective in bringing people to campus instead of having to find suitable places outside campus facilities. Participatory design, when practiced in full, should not only involve users (Halskov and Brodersen Hansen, 2015). It also gives the users voice in designing mock-ups and pilots Simonsen and Robertson, 2012) and in discussing the pros and cons to inform improvements from early on in the process (Simonsen and Robertson, 2012).

\section{Future research}

More solid research is needed to understand better the alignment of facilities management and educational leadership when designing for existing or new learning environments. This could be achieved by international comparisons of campuses and the practices that have led to successful outcomes in different contexts. In addition, the methods applied in learning environment and campus change should be reconsidered: qualitative and interview-based research is time-consuming, and questionnaires are either left unanswered or only produce superficial understanding of what users mean when they refer to activities and practices that support their working and learning. The tools might entail mixed methods that combine physical measurements with user selfreport experience sampling, thus deepening our understanding of what user rapport actually is saying about the facilities. It would also be beneficial to develop tools that support improved space awareness in users, thus providing them with a language and concepts regarding multidisciplinary collaboration - a prerequisite for successful change processes.

It is now 20 years since Duderstadt wrote his overview about changing universities according to needs that he listed accurately and, indeed, precisely in ways that are still being discussed in campus development. The way we think about university teaching and learning now and how we think they should change - from frontal teaching and mass lectures to more group-oriented knowledge co-creation and collaboration - could actually be seen as bringing us closer to how things used to be when the most common and efficient way of learning was through apprenticeship (Brown et al., 1989; Duderstadt, 1998; Lave and Wenger, 1991). It can well be asked: Who are the ones providing the learning and teaching environment in the future? How will pedagogies and credentialing change, and who is education designed for? One efficient way of ensuring that present and future aspirations are more consistently taken account of in the change process is to apply user-centred methods and co-design 
to produce designs that serve learning and support pedagogical approaches. Step by step, co-design can produce pedagogically meaningful future-ready solutions that are flexible and serve the users - transforming pedagogical needs into learning deeds.

\section{References}

Abeysekera, L. and Dawson, P. (2015), "Motivation and cognitive load in the flipped classroom: definition, rationale and a call for research", Higher Education Research and Development, Vol. 34 No. 1, pp. 1-14.

Beckers, R., Van der Voordt, T. and Dewurlf, G. (2015), "A conceptual framework to identify spatial implications of new ways of learning in higher education”, Facilities, Vol. 33 Nos 1/2, pp. 2-19.

Brown, M. and Long, P. (2006), "Trends in learning space design", in Oblinger, D.G. (Ed.), Learning Spaces, Educause, Boulder, CO, available at: www.educause.edu/ir/library/pdf/PUB7102i.pdf (accessed 30 May 2017).

Brown, J.S., Collins, A. and Duguid, P. (1989), "Situated cognition and the culture of learning", Educational Researcher, Vol. 18 No. 1, pp. 32-42.

Chiddick, D. (2006), The Fourth Founder's Lecture. Performing in a Blend of Virtual and Real Worlds, $D E G W$, London.

Council of Europe (2000), "European landscape convention. Florence, 20.X.2000”, European Treaty Series, No. 176, available at: https://rm.coe.int/1680080621

Deci, E.L. and Ryan, R.M. (2008), "Self-determination theory: a macrotheory of human motivation, development, and health", Canadian Psychology/Psychologie Canadienne, Vol. 49 No. 3, pp. 182-185, doi: 10.1037/a0012801.

den Heijer, A. (2011), Managing University Campus: Information to Support Real Estate Decisions, Eburon Academic Publishers, Delft.

Duderstadt, J.J. (1998), “Transforming the university to serve digital age”, CAUSE/EFFECT, Vol. 20 No. 4, pp. 21-32.

Dugdale, S. (2009), "Space strategies for the new learning landscape", EDUCAUSE Review, Vol. 44 No. 2, pp. 51-63.

Eriksson, R., Nenonen, S., Junghans, A., Balslev Nielsen, S. and Lindahl, G. (2015), “Nordic campus retrofitting concepts - scalable practices", Procedia Economics and Finance, Vol. 21, pp. 329-336.

Ertmer, P.A., Ottenbreit-Leftwich, A.T., Sadik, O., Sendurur, E. and Sendurur, P. (2012), "Teacher beliefs and technology integration practices: a critical relationship", Computers and Education, Vol. 59 No. 2, pp. 423-435.

Furco, A. and Moely, B.E. (2012), "Using learning communities to build faculty support for pedagogical innovation: a multi-campus study", Journal of Higher Education, Vol. 83 No. 1, pp. 128-153.

Gay, J.L., Saunders, R.P. and Dowda, M. (2011), "The relationship of physical activity and the built environment within the context of self-determination theory", Annals of Behavioral Medicine, Vol. 42 No. 2, pp. 188-196, doi: 10.1007/s12160-011-9292-y.

Göçer, Ö., Hua, Y. and Göçer, K. (2015), "Completing the missing link in building design process: enhancing post-occupancy evaluation method for effective feedback for building performance", Building and Environment, Vol. 89, pp. 14-27.

Granath, J.Å., Arch, M., Lindahl, G.A. and Rehal, S. (1996), "From empowerment to enablement: an evolution of new dimensions in participatory design", Logistik Und Arbeit, Vol. 8 No. 2, pp. 16-20.

\section{Working and learning environments}


JCRE 22,1

Gros, B. (2016), "The design of smart educational environments", Smart Learning Environments, Vol. 3 No.1, pp. 1-11.

Halskov, K. and Brodersen Hansen, N. (2015), "The diversity of participatory design research practice at PDC 2002-2012", International Journal of Human-Computer Studies, Vol. 74, pp. 81-92.

Harrison, A. (2006), Fourth Annual Founder's Lecture. Working to Learn, Learning to Work: Design in Educational Transformation, DEGW, London.

Harrison, A. and Hutton, L. (2014), Design for the Changing Educational Landscape-Space, Place and the Future of Learning, Routledge Taylor and Francis Group, London and New York, NY.

Hay, R., Samuel, F., Watson, K.J. and Bradbury, S. (2017), "Post-occupancy evaluation in architecture: experiences and perspectives from UK practice”, Building Research and Information, Vol. 46 No. 6, pp. 698-710, doi: 10.1080/09613218.2017.1314692.

Hoendervanger, J.G., De Been, I., Van Yperen, N.W., Mobach, M.P. and Albers, C.J. (2016), "Flexibility in use: switching behaviour and satisfaction in activity-based work environments", Journal of Corporate Real Estate, Vol. 18 No. 1, pp. 48-62.

Kärnä, S., Julin, P. and Nenonen, S. (2013), "User satisfaction on a university campus by students and staff”, Intelligent Buildings International, Vol. 5 No. 2, pp. 69-82.

Kojo, I. and Nenonen, S. (2012), "Workplaces for social ecosystems: user experiences in co- working places", Proceedings of EFMC2012, Copenhagen, 23-25 May.

Kojo, I. and Nenonen, S. (2016), "Typologies for co-working spaces in Finland - what and how?", Facilities, Vol. 34 Nos 5/6, pp. 302-313, doi: 10.1108/F-08-2014-0066.

Könings, K.D., Seidel, T. and van Merriënboer, J.J.G. (2014), "Participatory design of learning environments: integrating perspectives of students, teachers, and designers", Instructional Science, Vol. 42 No. 1, pp. 1-9.

Kuntz, A.M., Petrovic, J.E. and Ginocchio, L. (2012), "A changing sense of place: a case study of academic culture and the built environment", Higher Education Policy, Vol. 25 No. 4, pp. 433-451.

Lave, J. and Wenger, E. (1991), Situated Learning. Legitimate Peripheral Participation, Cambridge University Press, Cambridge.

McLaughlin, P., Faulkner, J. (2012), "Flexible spaces ... what students expect from university facilities", Journal of Facilities Management, Vol. 10 No. 2, pp. 140-149.

Maslow, A.H. (1970), Motivation and Personality, Harper and Row, New York, NY.

Matthews, K.E., Andrews, V. and Adams, P. (2011), "Social learning spaces and student engagement", Higher Education Research and Development, Vol. 30 No. 2, pp. 105-120.

Neary, M. and Saunders, G. (2011), "Leadership and learning landscapes: the struggle for the idea of the university", Higher Education Quarterly, Vol. 65 No. 4, pp. 333-352.

Nenonen, S., Eriksson, R., Niemi, O., Junghans, A., Nielsen, S.B. and Lindahl, G. (2016), "Campus retrofitting (CARE) methodology: a way to co-create future learning environments", In Proceedings of the 20th CIB World Building Congress 2016.

Nenonen, S. and Lindahl, G. (2014), "Competencies for multi-, inter- and transdisciplinary research in facilities management research", International Journal of Facilities Management, pp. 271-278. Published by EuroFM, available at: www.researchgate.net/ publication/264695969_EuroFM_Research_Papers

Paavola, S. and Hakkarainen, K. (2005), "The knowledge creation metaphor - an emergent epistemological approach to learning", Science and Education, Vol. 14 No. 6, pp. 535-557.

Patton, M. (1990), Qualitative Evaluation and Research Methods, Sage, Beverly Hills, CA. 
Pred, A. (2014), "The social becomes the spatial, the spatial becomes the social", in Gieseking, J. and Mangold, W. with Katz, C., Low, S. and Saegert, S. (Eds), The People, Place and Space Reader, Routledge, New York, NY and London, pp. 128-132.

Ryan, R.M. and Deci, E.L. (2002), "Overview of self-determination theory: an organismic-dialectical perspective", in E.L. Deci and R.M. Ryan (Eds), Handbook of Self-Determination Research, pp. 3-33, University of Rochester Press, Rochester, New York, NY.

Rytkönen, E. (2015), "University campuses in spatial transformation. A business model typology of case aalto university", Facilities, Vol. 33 Nos 13/14, pp. 794-818.

Working and learning environments

Rytkönen, E., Heywood, C. and Nenonen, S. (2016), "Campus management process dynamics - Finnish and australian practices", Journal of Corporate Real Estate, Vol. 19 No. 2, pp. 80-94.

Rytkönen, E., Nenonen, S., Österlund, E. and Kojo, I. (2015), "Process dynamics of managing interdisciplinary, cross-organizational learning campus in change: case aalto university", Facilities, Vol. 33 Nos 11/12, pp. 752-772.

Samson, D. (2013), "From the ivory tower to activity based workspaces", International Journal of Information and Education Technology, Vol. 3 No. 6, pp. 624-626.

Sanders, E.B.-N. and Stappers, P.J. (2008), "Co-creation and the new landscapes of design", CoDesign, Vol. 4 No. 1, pp. 5-18, doi: 10.1080/15710880701875068.

Sandström, N. and Nenonen, S. (2019), "What is a hub? Developing a tool for mapping out hub typologies", Intelligent Buildings.

Sandström, N. and Nevgi, A. (2017), "Tulevaisuuden yliopisto - käänteinen oppiminen keikauttaa kampuksen, [the university of the Future - Flipped learning flips the campus, published in Finnish]", Yliopistopedagogiikka - Journal of University Pedagogy, Vol. 24 No. 2, pp. 47-51.

Sandström, N., Ketonen, E. and Lonka, K. (2014), "The experience of laboratory learning - how do chemistry students perceive their learning environment?", The European Journal of Social and Behavioural Sciences, Vol. 11 No. 4, pp. 1612-1625.

Sandström, N., Eriksson, R., Lonka, K. and Nenonen, S. (2016), "Usability and affordances for inquiry-based learning in a blended learning environment", Facilities, Vol. 34 Nos 7/8, pp. $433-449$.

Sankari, I., Peltokorpi, A. and Nenonen, S. (2018), "A call for co-working - users' expectations regarding learning spaces in higher education”, Journal of Corporate Real Estate, Vol. 20 No. 2, pp. 117-137, doi: 10.1108/JCRE-03-2017-0007.

Savanick, S., Strong, R. and Manning, C. (2008), "Explicitly linking pedagogy and facilities to campus sustainability: lessons from Carleton college and the university of Minnesota", Environmental Education Research, Vol. 14 No. 6, pp. 667-679.

Scholl, K.G. and Gulwadi, G.B. (2018), "College campus landscapes within a learning ecosystem", Planning for Higher Education, Vol. 46 No. 2, pp. 50-64.

Simonsen, J. and Robertson, T. (2012), Routledge Handbook of Participatory Design Routledge, Routledge, London.

Sjöblom, K., Mälkki, K., Sandström, N. and Lonka, K. (2016), "Does physical environment contribute to basic psychological needs? A self-determination theory perspective on learning in the chemistry laboratory", Frontline Learning Research, Vol. 4 No. 1, pp. 17-39.

Skogland, M.A.C. and Hansen, G.K. (2017), "Change your space, change your culture: exploring spatial change management strategies", Journal of Corporate Real Estate, Vol. 19 No. 2, pp. 95-110.

Vallés-Planells, M., Galiana, F. and Van Eetvelde, V. (2014), "A classification of landscape services to support local landscape planning”, Ecology and Society, Vol. 19 No. 1, doi: 10.5751/ES-06251190144. Art. 44.

Van Note Chism, N. (2006), Challenging Traditional Assumptions and Rethinking Learning Spaces, in Oblinger, G. (Ed.), Learning Spaces, pp. 2.1-2.12. 
JCRE 22,1

Visser, S.F., Stappers, P.J., Van der Lugt, R. and Sanders, E.B.N. (2005), “Contextmapping: experiences from practice", CoDesign, Vol. 1 No. 2, pp. 119-149.

$\mathrm{Wu}, \mathrm{W}$. (2018), "Sharing or integration: rethinking the localization of co-working spaces in Shanghai", in Martin, L. and Wilson, N. (Eds), The Palgrave Handbook of Creativity at Work, Palgrave Macmillan, Cham, pp. 223-243.

Yin, R. (2009), Case Study Research: Design and Methods, 4th ed., Sage, Thousand Oaks, CA.

Young, C.A., Shinnar, R.S., Ackerman, R.L., Carruthers, C.P. and Young, D.A. (2007), "Implementing and sustaining service-learning at the institutional level", Journal of Experiential Education, Vol. 29 No. 3, pp. 344-365.

\section{Corresponding author}

Niclas Sandström can be contacted at: niclas.sandstrom@helsinki.fi

For instructions on how to order reprints of this article, please visit our website: www.emeraldgrouppublishing.com/licensing/reprints.htm

Or contact us for further details: permissions@emeraldinsight.com 